\title{
CONSERVATIVE MANAGEMENT OF THE URINARY BLADDER AMONG CHILDREN WITH SPINAL CORD INJURY
}

\author{
A. Estin Comarr, M.D. \\ From the Spinal Cord Injury Service, Veterans Administration Hospital, Long Beach, \\ California; the Urology Service, Rancho Los Amigos Hospital, Downey, California; the \\ Department of Surgery (Neurological-Urology), School of Medicine, University of Southern \\ California, Los Angeles, California and the Department of Urology, School of Medicine, \\ Loma Linda University, Loma Linda, California
}

THE purpose of this communication is to present the at random results of excretory pyelography among children with spinal cord injury who have not been treated with by-pass operations such as the ileal conduit or cutaneous vesicostomy.

\section{METHOD AND MATERIAL}

Each kidney of the intravenous pyelogram was graded from 0 to 4 ; 0 indicated that the kidney was essentially normal: grades I to 4 indicated degrees of pathology, ranging from grade $I$, indicating occasional blunting of the calices to grade 4 which indicated severe hydronephrosis, non-functioning, atrophy or nephrectomy.

The patients were studied as they were brought into the clinic. Each had a neurological examination by the author to determine the segmental level of injury; the completeness or incompleteness of the lesion; whether sacral sensory sparing; external rectal sphincter tone; and volitional control of the external rectal sphincter were present or not. Those intravenous pyelograms taken shortly before the neurological examination were interpreted and recorded. The method of bladder evacuation was also determined.

Twenty-eight patients, I 3 males and I 5 females, were studied with the age at injury ranging from birth to I 5 years. The time from injury to their present age ranged from six weeks to 35 years. Eight patients had complete cervical lesions; two had incomplete cervical lesions; eleven had complete thoracic I to 6 lesions and seven patients had complete thoracic 7 to 12 lesions. Twenty-three patients had upper motor neuron bladders and five patients lower motor neuron bladders.

\section{RESULTS}

Thirty-eight (68 per cent.) of the 56 kidneys were normal.

Seventeen (6I per cent.) of the 28 patients had normal kidneys bilaterally, and of these six had complete cervical lesions; one had an incomplete cervical lesion; seven had incomplete lesions in the thoracic I to 6 levels and three had complete lesions in the thoracic 7 to 12 levels. Seven patients were males and ten were females. The age at injury ranged from birth to I5 years (Table I) and the time injured ranged from six weeks to $12 \frac{1}{2}$ years (Table II). The type of evacuation of the bladder is shown in Table III.

Eleven, six male, five female ( 39 per cent.) of the 28 patients had pathology in one or both kidneys. Four ( 18 per cent.) of the 22 kidneys were normal and 18 
TABLE I

Normal Kidneys (SCI) Bilaterally

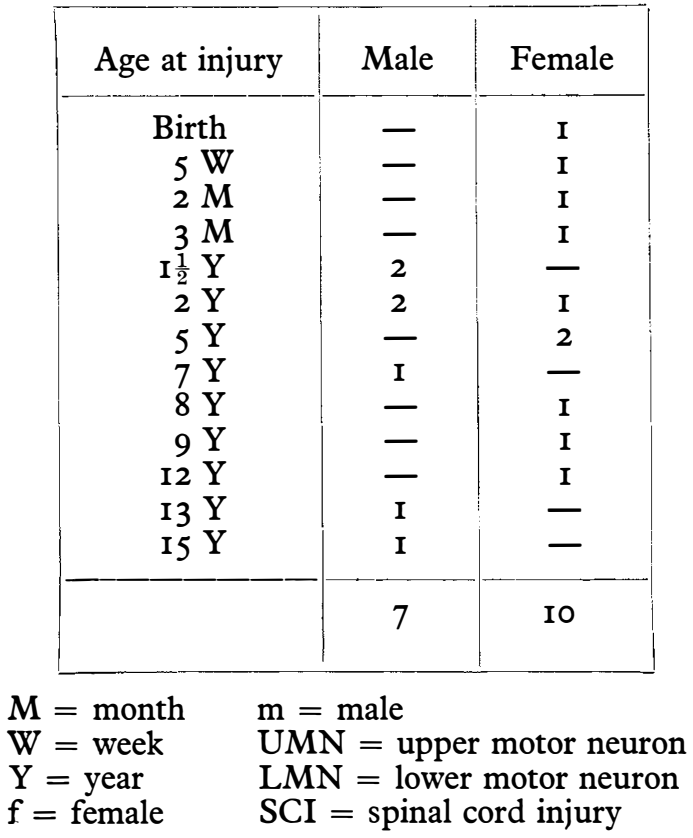

TABLE II

Normal Kidneys (SCI) Bilaterally

\begin{tabular}{|c|c|c|}
\hline \multirow{2}{*}{ Time of injury } & \multicolumn{2}{|c|}{ Type of bladder } \\
\hline & UMN & $\mathrm{LMN}$ \\
\hline $\begin{array}{r}6 \mathrm{~W} \\
\mathrm{I} \mathrm{Y} \\
\mathrm{I} \frac{1}{4} \mathrm{Y} \\
2 \mathrm{Y} \\
2 \frac{1}{4} \mathrm{Y} \\
3 \mathrm{Y} \\
4 \mathrm{Y} \\
5 \mathrm{Y} \\
6 \mathrm{Y} \\
7 \frac{1}{2} \mathrm{Y} \\
9 \mathrm{Y} \\
\mathrm{I} 2 \frac{1}{2} \mathrm{Y}\end{array}$ & $\begin{array}{l}\text { I (m) } \\
\text { I (f) } \\
\text { I (f) } \\
2 \text { (f) I (m) } \\
\text { I (f) } \\
\text { I (f) } \\
\text { I (f) } 2(\mathrm{~m}) \\
\text { I (f) } \\
\text { I (f) } \\
\text { I (f) I(m) } \\
\text { I (m) }\end{array}$ & $\mathbf{I}(\mathrm{m})$ \\
\hline & IO (f) $6(\mathrm{~m})$ & $\mathrm{I}(\mathrm{m})$ \\
\hline
\end{tabular}

Abbreviations as in Table I. 
( 82 per cent.) of the 22 kidneys had had pathology of some degree. Two of the patients had complete cervical lesions; one had an incomplete cervical lesion; four had complete lesions in the thoracic I to 6 levels and four had complete lesions in

TABLE III

Normal Kidneys (SCI) Bilaterally

\begin{tabular}{|c|c|c|c|}
\hline \multirow{2}{*}{ Time of injury } & \multicolumn{3}{|c|}{ Type of evacuation } \\
\hline & Catheter & Diapers & $\begin{array}{l}\text { External } \\
\text { appliance }\end{array}$ \\
\hline $\begin{array}{r}6 \mathrm{~W} \\
\mathrm{I} \mathrm{Y} \\
\mathrm{I} \frac{1}{4} \mathrm{Y} \\
2 \mathrm{Y} \\
2 \frac{1}{4} \mathrm{Y} \\
3 \mathrm{Y} \\
4 \mathrm{Y} \\
5 \mathrm{Y} \\
6 \mathrm{Y} \\
7 \frac{1}{2} \mathrm{Y} \\
9 \mathrm{Y} \\
\mathrm{I} 2 \frac{1}{2} \mathrm{Y}\end{array}$ & I (f) & $\begin{array}{l}\text { I (f) } \text { I (m) } \\
\text { I (f) } \\
\text { 2 (f) } \\
\text { I (f) } \\
\text { I (f) } \\
\text { I (f) I (m) } \\
\text { I (f) } \\
\text { I (f) }\end{array}$ & $\begin{array}{l}\text { I (m) } \\
\text { I (m) } \\
\text { I (m) } \\
\text { I (m) } \\
\text { I (m) }\end{array}$ \\
\hline & I (f) & $9(\mathrm{f}) 2(\mathrm{~m})$ & $5(\mathrm{~m})$ \\
\hline
\end{tabular}

Abbreviations as in Table I.

TABLE IV

Pathology in One or Both Kidneys (SCI)

\begin{tabular}{|c|c|c|}
\hline Age at injury & Male & Female \\
\hline Birth & & I \\
2 Y & I & I \\
9 Y & I & I \\
IO Y & I & I \\
I2 Y & 2 & I \\
I5 Y & I & I \\
\hline & 6 & 5 \\
\hline
\end{tabular}

Abbreviations as in Table I.

the thoracic 7 to 12 levels. The age at injury ranged from birth to 15 years (Table IV) and the time injured ranged from nine to thirty-five years (Table V). Table VI shows the type of bladder evacuation and Table VII shows the degree of pathology in relation to the age at injury and the length of time the patient has been a spinal cord injury patient. 
TABLE V

Pathology in One or Both Kidneys (SCI)

\begin{tabular}{|c|c|c|}
\hline \multirow{2}{*}{ Time of injury } & \multicolumn{2}{|c|}{ Type of bladder } \\
\hline & UMN & LMN \\
\hline $\begin{array}{l}9 \mathrm{Y} \\
9 \frac{1}{2} \mathrm{Y} \\
10 \mathrm{Y} \\
12 \mathrm{Y} \\
19 \mathrm{Y} \\
20 \mathrm{Y} \\
33 \mathrm{Y} \\
35 \mathrm{Y}\end{array}$ & $\begin{array}{l}\text { I (f) } \\
\text { I (m) } \\
2(\mathrm{f}) \\
\text { I (f) }\end{array}$ & I (f) $2(\mathrm{~m})$ \\
\hline & $4(\mathrm{f}) 3(\mathrm{~m})$ & I (f) $3(\mathrm{~m})$ \\
\hline
\end{tabular}

Abbreviations as in Table I.

TABLE VI

Pathology in One or Both Kidneys (SCI)

\begin{tabular}{|c|c|c|c|}
\hline \multirow{2}{*}{ Time of injury } & \multicolumn{3}{|c|}{ Type of evacuation } \\
\hline & \multicolumn{2}{|c|}{ Catheter } & Bricker \\
\hline $\begin{array}{l}9 \mathrm{Y} \\
9 \frac{1}{2} \mathrm{Y} \\
10 \mathrm{Y} \\
12 \mathrm{Y} \\
19 \mathrm{Y} \\
20 \mathrm{Y} \\
33 \mathrm{Y} \\
35 \mathrm{Y}\end{array}$ & $\begin{array}{l}\text { I (f) Intra } \\
\text { I Intra } \\
\text { 2 (f) I Supra } \\
\text { I (f) } 3 \text { Y Intra }\end{array}$ & $\begin{array}{l}\text { I (m) Supra } \\
\text { I (m) Intra } \\
2 \text { (m) Supra } \\
\text { I (m) Intra } \\
\text { I (m) Supra }\end{array}$ & I (f) \\
\hline & $4(f)$ & $6(\mathrm{~m})$ & I (f) \\
\hline
\end{tabular}

Abbreviations as in Table I.

Intra $=$ Intraurethral catheter.

Supra $=$ Suprapubic catheter.

Bricker $=$ ileal conduit operation. 
TABLE VII

Pathology in One or Both Kidneys (SCI)

\begin{tabular}{|c|c|c|c|c|c|}
\hline \multirow{2}{*}{$\begin{array}{l}\text { Age at } \\
\text { injury }\end{array}$} & \multirow{2}{*}{$\begin{array}{l}\text { Time of } \\
\text { injury }\end{array}$} & \multicolumn{2}{|c|}{$\begin{array}{l}\text { Degree of pathology } \\
\text { (Kidney) }\end{array}$} & \multirow{2}{*}{ Male } & \multirow{2}{*}{ Female } \\
\hline & & Right & Left & & \\
\hline $9 \mathrm{Y}$ & $9 \mathrm{Y}$ & 2 & I & $x$ & \\
\hline $2 \mathrm{Y}$ & $9 \frac{1}{2} \mathrm{Y}$ & I & Nephrectomy & & $\times(\mathrm{Br})$ \\
\hline $\mathrm{I}_{2} \mathrm{Y}_{1}$ & IO Y & $\left(\frac{1}{2}\right.$ & 0 & $x$ & \\
\hline I5 Y & & $\sqrt{2}$ & 2 & & $x$ \\
\hline $2 Y_{1}$ & $12 \mathrm{Y}$ & $\int 2 \frac{1}{2}$ & $2 \frac{1}{2}$ & $\times$ & \\
\hline I2 Y & & (I & 2 & $\times$ & \\
\hline Birth $_{1}$ & I9 $\mathrm{Y}$ & 2 & 0 & & $x$ \\
\hline $9 \mathrm{Y}\}$ & & 10 & $\frac{1}{2}$ & & $x$ \\
\hline $15 \mathrm{Y}$ & $20 \mathrm{Y}$ & I & $2 \frac{1}{2}$ & $x$ & \\
\hline I2 Y & $33 \mathrm{Y}$ & 2 & 0 & & $x$ \\
\hline I0 $\mathrm{Y}$ & $35 \mathrm{Y}$ & $I_{2}^{\frac{1}{2}}$ & 3 & $\times$ & \\
\hline
\end{tabular}

Abbreviations as in Table I.

$\mathrm{Br}=$ Ileal Conduit (Bricker Operation).

\section{DISCUSSION}

Sixty-eight per cent. of the 56 kidneys were normal. Of the 32 per cent. of the kidneys showing pathology there was only one grade 4 , and this was because of a nephrectomy of which we were unable to ascertain why it had been performed elsewhere. After the nephrectomy the urologist performed an ileal conduit operation. This by-pass operation was included in the series since the nephrectomy had already been performed. The indication for the by-pass could not be ascertained.

In Table VII it should be noted that there is only one kidney with a grade 3. The other degrees of pathology can carry these patients for many years if they are urologically examined periodically and complications are managed as indicated. If one considers grade 3 and 4 kidneys as poor kidneys, then of the entire amount, 54 (96 per cent.) showed adequate function to sustain life for many years in the majority of the patients.

In this study one patient was injured $12 \frac{1}{2}$ years with bilaterally normal kidneys. The shortest period of injury to show pathology was of nine years duration.

Two patients when studied were 45 years old; one had been injured at the age of Io and for 35 years had kidneys graded as, right $I_{2} \frac{1}{2}$ and left 3 . The other patient had been injured at the age of 12 years and after 33 years one kidney was graded as a 2, the other normal.

This investigator purposely divided the study into two groups to show the effect of catheters. If Table III is compared with Table VI, it is self-evident that most of the patients with pathological kidneys were on some type of catheter drainage (intraurethral or suprapubic) whereas in the case of bilaterally normal kidneys there was only one. Yet, it remains incumbent upon those who prefer 
by-pass operations to prove their method is far superior to conservative management. The reader must be reminded that the patients in this study were studied at random and had not been under the constant surveillance of the author since time of injury.

Two patients had kidney stones. One who had been on a suprapubic catheter from a birth injury until I9 years of age was found to have a stone in the lower calyx of the right kidney. Another patient who was 35 years of age and had been injured at the age of 15 had had stones removed once on the right and twice on the left kidney.

One patient with a complete lesion at thoracic 4 and an upper motor neuron bladder was injured at age $\mathrm{I} \frac{1}{2}$ and at the time of examination, age $\mathrm{I} 4$, his kidneys were normal bilaterally. He had never been on a catheter and when he was seven years of age he had been able to use an external appliance. His reflex bladder at birth has persisted till time of examination-I4.

Only one of these patients had ischial ulcers. These were not due to poor hygiene but rather to trauma following a fall when the patient fell on to the ischial sites.

\section{SUMMARY}

The excretory pyelograms of 28 patients who had sustained spinal cord injuries during childhood were studied at random. They had not been managed entirely at the author's clinics. The age at injury ranged from birth to 15 years. The period of injury ranged from six weeks to 35 years. Thirty-eight (68 per cent.) of the 56 kidneys were normal. Seventeen (6I per cent.) of the 28 patients had normal kidneys bilaterally. Eleven ( 39 per cent.) of the 28 patients had pathology in one or both of the kidneys; only two patients had a single kidney which was considered 'poor'.

\section{CONSERVATIVE MANAGEMENT OF THE URINARY BLADDER IN MYELODYSPLASIA}

\section{A. Estin Comarr, M.D.}

THIS communication's purpose is to present the results of excretory pyelography among patients with myelodysplasia who have not been treated with by-pass operations such as ileal conduits (Bricker operation) or cutaneous vesicostomies. These patients were seen in clinics by this investigator at random and each was given a neuro-urological examination. The excretory pyelograms performed shortly before the examination were interpreted and the findings recorded.

\section{METHOD AND MATERIAL}

Each kidney of the intravenous pyelogram was graded from 0 to 3; 0 indicating an essentially normal kidney. Grades I to 3 represented degrees of pathology, ranging from Grade I which indicated blunting of the calices to Grade 3 which indicated gross hydronephrosis, non-functioning nephrectomy, or atrophy. 